\title{
Lipid-Lowering Property of Flavonoid-Rich Portion of Combretum Micranthumon High Fat Diet Induced Hyperlipidemic Rats
}

\author{
Abba Babandi*, NajibullahDanjuma Musa, MurtalaYa'u, Hafeez Muhammad Yakasai, Dayyabu \\ Shehu, Kamaludden Babagana, Aminu Ibrahim \\ Department of Biochemistry, Bayero University, PMB 3011, Kano, Nigeria. \\ * Corresponding author. Tel. +2348086303170; email: ababandi.bch@buk.edu.ng \\ Manuscript submitted May 1, 2018; accepted October 9, 2018. \\ doi: 10.17706/ijbbb.2019.9.1.42-50
}

\begin{abstract}
The lipid-lowering potential of flavonoid-rich portion of Combretum micranthum (CM) on a high-fat diet (HFD) induced albino rats was evaluated. Hyperlipidaemic rats were divided into six groups. Group I (Normal control), group II (HFD-fed only), while group III, IV and V received aqueous methanol $(80 \%)$ leaf extract of CM at varied doses of 100, 200 and $400 \mathrm{mg} / \mathrm{kg}$, respectively, while group VI were given the standard drug- Atorvastatin ( $4 \mathrm{mg} / \mathrm{kg}$ ) for two weeks. Total Cholesterol (TC), Triacylglycerol (TAG), High Density Lipoproteins (HDL-C), Creatine Kinase (CK), and Lactate Dehydrogenase (LDH) were assayed spectrophotometrically and Atherogenic Index (AI) calculated using standard formula. GC-MS revealed 2,3-dihydro-3,5-dihydroxy-6-methyl-4H-pyran-4-one, 5-oxycatechol and 1,2,3- benzene- triol to be the principal compounds. Significant reduction in TC, TAG, LDL-C, AI, CK, LDH and increased in HDL-C were observed compared to hyperlipidemic control $(\mathrm{p}<0.05)$ hence $\mathrm{CM}$ could be used in the management of risk of CVDs.
\end{abstract}

Key words: Combretummicranthum, flavonoids, GC-MS, hyperlipidemia.

\section{Introduction}

One of the major risk contributing factors for the prevalence of cardiovascular diseases (CVDs) is hyperlipidemia [1]. Many factors such as diet (rich in saturated fat and cholesterol), age, family disease history, hypertension, and life style play a major role in the development of high cholesterol and LDL levels, which are critically responsible for the onset of atherosclerosis and coronary heart diseases [2] as well as cardiovascular diseases [3]. Hypercholestorelemia is a dominant risk factor widely known for the development of cardiovascular diseases [4], which is leading cause of death in developing and developed countries [5]. Hyperlipidemia which mostly induces oxidative stress is now believed to have an important role in the development of non-alcoholic fatty liver diseases (NAFLD) which is the most common liver disorders in the world and in obesity, diabetes mellitus type 2 and other closely related metabolic disorders, its incidence reaches 70-90\% [6]. Many researchers have sought to identify which parameters are most closely correlated with an increased risk of CVDs. Elevated level of serum total cholesterol (TC) and low density lipoprotein (LDL-C) levels, low serum high density lipoprotein (HDL-C) and high serum triacylglycerides (TAGs) levels have been correlated to increased incidences of hyperlipidemia and cardiovascular diseases [7]. Recently, Atherogenic index (AI) has started to gain importance as an indicator of atherosclerosis; as it's less susceptible to disease activity variation during long periods of time; making it 
more attractive to be used in CVDrisk prediction in patients as compared with lipids concentrations [8]. Alterations in the level of CK and LDH are also some of the biochemical indices that are often used in the prediction of CVD risk [9]. Lowering of lipids levels by drugs and/or diet management could reduce the risk of CVDs. Researchers were encouraged by current awareness of medicinal plants in the management of CVDs which lead to exploring novel lipid lowering pharmaceuticals [10]. Since time immemorial, plants are indiscriminately used worldwide in the treatment of various diseases including hyperlipidemia without any scientific reasons. Current use of hypolipidemic drugs are associated with adverse effects and withdrawal is associated with rebound phenomenon which is not seen with herbal preparations and the high cost of many synthetic drugs has become a global case especially in developing countries, hence, there is need for the alternatives. The need to ascertain the potency of these plant extracts in the treatment of diseases become imperative.This research study aimed to establish antihyperlipidemic activity of flavonoid-rich extract of $C M$ plant from Nigeria.

\section{Materials and Methods}

\subsection{Plant Material, Collection and Identification}

The plant materials were obtained from filinshagari in Bauchi state, Nigeria and was authenticated and identified at BiologicalSciences Department, Bayero University, Kano(BUK), with voucher No. BUKHANO272. The plant materials were shade dried at room temperature for 10 days, coarsely powdered, and the powder was sieved and used for extraction. The powdered sample material was extracted using $80 \%$ aqueous methanol. The dried extract was then kept in air tight container and placed in refrigerator.

\subsection{Experimental Animals Acquisition and Care}

Apparently healthy albino rats (24) of bothsexes were obtained from the animal house, Department of Biological Sciences, Bayero University Kano. After randomization to various groups and before the initiation of the experiment, the rats were acclimatized for a period of 7 days under standard environmental conditions of $25^{\circ} \mathrm{C}$ temperature, $65 \%$ relative humidity, and 12 hours day/night cycle with spacious cages. The animals were given feed and water adlibitum and they were handled according to international guidelines [11], [12].

\subsection{Preparation of the Extract}

\subsubsection{Extraction of flavonoids from combretummicranthum}

Dried powdered leaves sample, $(50 \mathrm{~g})$ was extracted with $300 \mathrm{ml}$ of $80 \%$ aqueous methanol at room temperature. It was then filtered through whatman filter paper No. $42(125 \mathrm{~mm})$ and the filtrate was transferred into a crucible for drying in water bath, which was then dried to a constant weight in an oven [13].

\subsubsection{Qualitative determination of flavonoids}

- From the plant's powder:

To distilled water, $1.0 \mathrm{~g}$ of the sample was added boiled and filtered. Few drops of $10 \%$ ferric chloride solution were added to $2 \mathrm{ml}$ of the mixture. Green-blue coloration was formed which indicate the presence of flavonoids.

- From the extract:

To distilled water, $0.5 \mathrm{~g}$ of the sample was added, boiled, and filtered. Few drops of $10 \%$ ferric chloride solution were added to $2 \mathrm{ml}$ of the mixture. Green-blue coloration was formed which indicate the presence of flavonoids.

\subsubsection{Quantitative determination of flavonoids in combretummicranthum}


- From the Plant Powder:

Two(2) g of the sample was extracted with $100 \mathrm{ml}$ of $80 \%$ aqueous methanol at room temperature. It was then filtered through whatman filter paper No. $42(125 \mathrm{~mm})$ and the filtrate was transferred into a crucible for drying in water bath and later, dried to constant weight in an oven [13]. The dried extract was then weighed and the amount of flavonoids extracted was calculated.

- From the flavonoids rich extract:

Two(2) g of the extract was re-extracted with $20 \mathrm{ml}$ of $80 \%$ aqueous methanol at room temperature. It was then filtered through whatman filter paper No. $42(125 \mathrm{~mm})$ and the filtrate was transferred into a crucible for drying in water bath, which was then dried to constant weight in an oven [13]. The dried extract was then weighed and the amount of flavonoids extracted was calculated.

$$
\% \text { flavonoid }=\frac{\text { weight of dried residue }(\text { extract })}{\text { weight of the original sample }} \times 100 \%
$$

\subsection{Experimental Design and Grouping}

The experimental animals were weighed and grouped into 6 groups;

Group I: consist of 4 animals that are not induced with hyperlipidemia and they are fed with normal diet and water for 6 weeks. They serve as normal control group-I.

Group II: consist of 4 animals that were induced with hyperlipidemia for 3 weeks and were not treated. They serve as negative control group-II.

GroupIII: were induced with hyperlipidemia for 3 weeks and administered with flavonoid at a dose of $100 \mathrm{mg} / \mathrm{kg}$ (low dose) for 2 weeks.

GroupIV: were induced with hyperlipidemia for 3 weeks and administered with flavonoid at a dose of $200 \mathrm{mg} / \mathrm{kg}$ (median dose) for 2 weeks.

Group V: were induced with hyperlipidemia for 3 weeks administered with flavonoid at a dose of $400 \mathrm{mg} / \mathrm{kg}$ (high dose) for 2 weeks.

Group VI: consist of 4 animals that were induced with hyperlipidemia for 3 weeks and treated with atorvastatin for 2 weeks.

All these doses were administered intragastrically to the rats once daily, and rats in an untreated group were continuously fed with high fat diet, while rats in normal control were continuously fed with normal diet and water. At the end of the experiment, the experimental animals were starved for $12 \mathrm{~h}$ before sacrifice. The blood sample was collected into plastic plane bottles.

\subsection{Formulation of High-Fat Diet (HFD)}

The HFD was formulated as shown in the Table 1 [14].

Table 1. High-Fat Diet (HFD) Formulation

\begin{tabular}{lll}
\hline Food content & Percentage & Amount \\
\hline Animal fed grower (chicken grower) & $58 \%$ & $580 \mathrm{~g}$ \\
Palm oil & $7.6 \%$ & $76 \mathrm{ml}$ \\
Egg yolk & $31 \%$ & $310 \mathrm{ml}$ \\
Coconut oil & $3.3 \%$ & $33 \mathrm{ml}$ \\
\hline
\end{tabular}

\subsection{Collection of Blood, Preparation of the Serum and Biochemical Estimations}

After 6 weeks of the experiment, the animals were sacrificed and blood sample was collected from all the groups after 12 hours fasting. The blood sample was collected into plane bottles and allowed to clot for 
45 minute at room temperature and centrifuged at $3000 \mathrm{rpm}$ for 20 minutes. The serum obtained was kept at $0^{\circ} \mathrm{C}$ until analyzed.

\subsection{Statistical Analysis}

All the data were expressed as mean \pm standard deviation (S.D). Statistical significance was calculated using one-way analysis of variance (ANOVA). Significance was accepted at $(\mathrm{P}<0.05)$.

\section{Results and Discussion}

This study evaluates the lipid-lowering potential of flavonoid-rich portion of Combretummicranthum(CM) in a high-fat diet induced hyperlipidaemic albino rats; and the results summarized in tables below.

Table 2. Qualitative and Quantitative Analysis of Flavonoid in Combretummicranthum Leaf Powder and the Methanol Leaf Extract

\begin{tabular}{lll}
\hline Flavonoid content & Qualitative & Quantitative (\%) \\
\hline Plant powder(50g) & + & $22.25 \pm 7.99$ \\
Extract $(2 \mathrm{~g})$ & + & $87.00 \pm 21.89$ \\
\hline
\end{tabular}

Table 2 Depicts quantitative and qualitative Analysis of flavonoids in both the plant powder and the methanol leaf extract of $C M$. The qualitative determination shows a presence of flavonoids. The quantitative amount of flavonoids in $50 \mathrm{~g}$ of the plant powder was found to be $22.25 \%$ of the total amount of the plant powder $(50 \mathrm{~g})$. Also, the amount of flavonoids in $2 \mathrm{~g}$ of methanol leaf extract of $\mathrm{CM}$ was $87 \%$ of the total extracts used(2g).

Table 3. GCMS Profile of Methanol Leaf Extract of C.micranthum

\begin{tabular}{|c|c|c|c|c|c|}
\hline $\mathrm{S} / \mathrm{N}$ & Compound & . & RT & PA & USES \\
\hline 1 & Propanol-3-methoxy-2,2-bis(methoxymethyl)- & $\mathrm{C}_{8} \mathrm{H}_{16} \mathrm{O}_{4}$ & 17.32 & 0.1 & $\begin{array}{l}\text { Powerful reducing agent, } \\
\text { with antioxidant property. }\end{array}$ \\
\hline 2 & 1,2,3- benzene- triol & $\mathrm{C}_{6} \mathrm{H}_{6} \mathrm{O}_{3}$ & 20.61 & 0.27 & $\begin{array}{l}\text { White crystalline } \\
\text { compound with powerful } \\
\text { reducing ability. }\end{array}$ \\
\hline 3 & 3-hydroxy-4-methoxy benzoic acid & $\mathrm{C}_{8} \mathrm{H}_{8} \mathrm{O}_{4}$ & 25.27 & 0.2 & $\begin{array}{l}\text { A molecular entity capable } \\
\text { of donating a proton to } \\
\text { acceptor. }\end{array}$ \\
\hline 4 & $\begin{array}{l}\text { Phenol-2,6-bis } \\
\text { carbamate }\end{array}$ & $\mathrm{C}_{17} \mathrm{H}_{27} \mathrm{~N} 02$ & 17.94 & 0.17 & $\begin{array}{l}\text { Use as an oral } \\
\text { anesthetic/analgesic }\end{array}$ \\
\hline & & & & & $\begin{array}{lrr}\text { commonly } & \text { used } & \text { to } \\
\text { temporarily } & & \text { treat }\end{array}$ \\
\hline & & & & & $\begin{array}{l}\text { pharyngitil. Use as } \\
\text { antiseptic }\end{array}$ \\
\hline 5 & $\begin{array}{l}\text { 2,6,10,15,19,23-hexamethyl-tetracosa-2,10,14,18, } \\
\text { 22-pentaene-6,7-diol. }\end{array}$ & $\mathrm{C}_{30} \mathrm{H}_{52} \mathrm{O}_{2}$ & 40.69 & 0.04 & $\begin{array}{l}\text { Play a role in the synthesis } \\
\text { of cholesterol and steroid } \\
\text { hormones. }\end{array}$ \\
\hline 6 & Hopane & $\mathrm{C}_{30} \mathrm{H}_{52}$ & 45.68 & 4.98 & $\begin{array}{l}\text { Influencing membrane } \\
\text { permeability and rigidity }\end{array}$ \\
\hline 7 & Methoxy-2,2-bis(methoxymethyl)- & $\mathrm{C}_{8} \mathrm{H}_{18} \mathrm{O}_{4}$ & 17.328 & 0.1 & $\begin{array}{l}\text { Kill or Slow down the } \\
\text { growth of bacteria. }\end{array}$ \\
\hline 8 & Phytol & $\mathrm{C}_{20} \mathrm{H}_{40} \mathrm{O}$ & 14.96 & 0.1 & $\begin{array}{l}\text { Precursor for the synthesis } \\
\text { of many vitamins }\end{array}$ \\
\hline 9 & Friedland-3-0ne & $\mathrm{C}_{30} \mathrm{H}_{50} \mathrm{O}$ & 37.01 & 0.01 & $\begin{array}{l}\text { Antimicrobial, and } \\
\text { antioxidant in most of the }\end{array}$ \\
\hline
\end{tabular}




\begin{tabular}{|c|c|c|c|c|c|}
\hline & & & & & organism tested \\
\hline 10 & Docsyl-dihydrofuran-2-0ne & $\mathrm{C}_{9} \mathrm{H}_{16} \mathrm{O}_{2}$ & 32.753 & 0.03 & Use as an antiseptic. \\
\hline 11 & $\begin{array}{l}\text { 2,3-dihydro-3,5-dihydroxy-6-methyl-4H-pyran-4- } \\
\text { one }\end{array}$ & $\mathrm{C}_{6} \mathrm{H}_{8} \mathrm{O}_{4}$ & 13.414 & 0.28 & $\begin{array}{l}\text { Antioxidant activity of this } \\
\text { active compound was } \\
\text { confirmed in many studies. }\end{array}$ \\
\hline 12 & 5-oxycatechol & $\mathrm{C}_{6} \mathrm{H}_{6} \mathrm{O}_{3}$ & 15.332 & 0.08 & $\begin{array}{l}\text { It is a phenol with strong } \\
\text { Antioxidant activity and } \\
\text { used to chelate metals. }\end{array}$ \\
\hline
\end{tabular}

\section{$\mathrm{MF}=$ molecular formular, $\mathrm{RT}=$ retention time, $\mathrm{PA}=$ peak area.}

The table showed different chemical compounds present in the flavonoid-rich extract of $C M$ by GC-MS with their respective molecular formula, retention time, peak area, and uses.

Table 4. Body Weight Changes of High Fat Diet Induced Hyperlipidenic Rat Administered with Flavonoid-Rich Portion of C.micranthumafter Induction, 1st Week and 2nd Week of the treatment

\begin{tabular}{|c|c|c|c|c|c|c|}
\hline \multirow[b]{2}{*}{ Groups } & \multirow{2}{*}{$\begin{array}{l}\text { Duration } \\
\text { Initial weight(g) }\end{array}$} & \multicolumn{3}{|l|}{ Week 1} & \multicolumn{2}{|l|}{ Week 2} \\
\hline & & Weight(g) & $\begin{array}{l}\text { Change in } \\
(\%) .\end{array}$ & weight & Weight(g) & Change in weight (\%) \\
\hline Group I & $167.5 \pm 8.54^{\mathrm{a}}$ & $180 \pm 8.17^{a}$ & $+4.78 \pm 0.28^{a}$ & & $197.5 \pm 4.78^{\mathrm{a}}$ & $+5.56 \pm 1.3^{\mathrm{a}}$ \\
\hline Group II & $212.5 \pm 13.15^{\mathrm{a}}$ & $232.5 \pm 6.29 a$ & $+11.94 \pm 2.21^{\mathrm{a}}$ & & $250 \pm 4.08^{\mathrm{a}}$ & $+9.85 \pm 1.00^{a}$ \\
\hline Group III & $210 \pm 14.72^{a}$ & $187.5 \pm 11.09 a$ & $-10.48 \pm 1.79 a$ & & $160 \pm 8.17 \mathrm{a}$ & $-17.61 \pm 1.86^{a}$ \\
\hline Group IV & $210 \pm 12.91^{a}$ & $190 \pm 12.91^{\mathrm{a}}$ & $-9.64 \pm 0.59 b$ & & $162.5 \pm 11.09^{a}$ & $-17.02 \pm 2.28 c$ \\
\hline Group V & $207.5 \pm 15.48^{a}$ & $187.5 \pm 11.09 \mathrm{a}$ & $-9.64 \pm 0.59 b$ & & $157.5 \pm 14.36^{\mathrm{e}}$ & $-18.41 \pm 2.72^{c}$ \\
\hline Group VI & $225 \pm 17.08^{b}$ & $202.5 \pm 14.93^{a}$ & $-9.84 \pm 1.93^{c}$ & & $167.5 \pm 12.5^{c}$ & $-17.29 \pm 0.68^{d}$ \\
\hline
\end{tabular}

Values were expressed as means \pm Standard Error Mean (SEM). Values with the same superscript along a row have no significant difference, while those with different superscript have significant difference. Only \% weight change of the groups is compared. Negative sign signifies decrease in weight, while those with positive (+) sign shows increase in weight.

Table-5. Lipid-Lowering Activity and Atherogenic Index of Flavonoid Extract of C.Micranthum and Atorvastatin on High Fat Diet InducedHyperlipidemic Albino Rats

\begin{tabular}{llllll}
\hline Groups & \multirow{2}{*}{$\mathrm{TC}(\mathrm{mmol} / \mathrm{l})$} & $\mathrm{TAG}(\mathrm{mmol} / \mathrm{l})$ & HDL-C $(\mathrm{mmo} / \mathrm{l})$ & LDL-C $(\mathrm{mmol} / \mathrm{l})$ & AI \\
\hline Group I (N-control) & $0.436 \pm 0.0995^{\mathrm{a}}$ & $0.821 \pm 0.0302^{\mathrm{a}}$ & $0.543 \pm 0.0894^{\mathrm{a}}$ & $0.336 \pm 0.0650^{\mathrm{a}}$ & $0.300 \pm 0.0630^{\mathrm{a}}$ \\
Group II(H-control) & $1.234 \pm 0.3701^{\mathrm{b}}$ & $1.638 \pm 0.3968^{\mathrm{b}}$ & $0.387 \pm 0.0780^{\mathrm{b}}$ & $0.961 \pm 0.6351^{\mathrm{b}}$ & $2.34 \pm 0.8160^{\mathrm{b}}$ \\
GroupIII(100mg/kg) & $0.281 \pm 0.0689^{\mathrm{c}}$ & $0.764 \pm 0.1544^{\mathrm{a}}$ & $0.620 \pm 0.1050^{\mathrm{a}}$ & $0.312 \pm 0.1170^{\mathrm{c}}$ & $0.707 \pm 0.2340^{\mathrm{c}}$ \\
GroupIV(200mg/kg) & $0.346 \pm 0.1349^{\mathrm{d}}$ & $0.819 \pm 0.1794^{\mathrm{a}}$ & $0.695 \pm 0.0320^{\mathrm{a}}$ & $0.315 \pm 0.0710^{\mathrm{d}}$ & $0.732 \pm 0.1530^{\mathrm{d}}$ \\
Group V(400mg/kg) & $0.314 \pm 0.1019^{\mathrm{e}}$ & $0.434 \pm 0.1539^{\mathrm{a}}$ & $0.739 \pm 0.0430^{\mathrm{c}}$ & $0.356 \pm 0.0930^{\mathrm{e}}$ & $0.452 \pm 0.1290^{\mathrm{e}}$ \\
GroupVI(120mg/kg & $0.426 \pm 0.0348^{\mathrm{f}}$ & $0.773 \pm 0.2371^{\mathrm{c}}$ & $0.539 \pm 0.0360^{\mathrm{a}}$ & $0.278 \pm 0.1390^{\mathrm{f}}$ & $0.155 \pm 0.0590^{\mathrm{f}}$ \\
\hline atorvastatin). & & & & & \\
\hline
\end{tabular}

Values are expressed as mean \pm SME; Values with different superscript letter $(\mathrm{a}, \mathrm{b}$ and $\mathrm{c}$ ) differ significantly at $\mathrm{p}<0.05$. ( $\mathrm{TC}=$ total cholesterol, $\mathrm{TAG}=$ triacyl glycerol, HDL-C high density lipoprotein-cholesterol,LDL-C= low density lipoprotein-cholesterol, $\mathrm{AI}=$ atherogenic index, $\mathrm{N}$-control= normal control, $\mathrm{H}$-control= hyperlipidemic control).

Table 4 shows body weights of high fat diet induced hyperlipidaemic rats after induction, $1^{\text {st }}$ week of treatment, $2^{\text {nd }}$ week of treatment together with $\%$ body weight change in the $1^{\text {st }}$ and $2^{\text {nd }}$ weeks of treatment. No significant difference $(\mathrm{p}<0.05)$ was observed in group I, II and III during the first and second weeks of the treatment. But there is a significant decrease in weight in group IV, V and VI (Table 4) during the second week of treatment compared to the first week.

Table 5depicts Lipid-lowering activity of flavonoid extract of $C$. micranthum and atorvastatin on serum 
lipid profile and antherogenic index of an induced hyperlipidemic albino rats. A significant decrease in total cholesterol is observed in all the treated groups (both flavonoid treated and atorvastatin treated groups) as compared to the hyperlipidemic control group (Table 5). There is also significant decrease in triglycerides in the group treated with dose $(200 \mathrm{mg} / \mathrm{kg})$ of flavonoid rich extract as compared to hyperlipidemic control $(p<0.05)$. Triglyceride level in the rest of the groups also decreased but not significantly. An extremely significant decrease in LDL-Cholesterol was observed in all the treated groups as compared to the hyperlipidemiccontrol $(\mathrm{p}<0.05)$. The AI extremely decreased significantly in the treated groups compared to hyperlipidemic control (Table 5). HDL-Cholesterol level increased significantly in flavonoids $(400 \mathrm{mg} / \mathrm{kg}$ ) treated group and atorvastatin group compared to hyperlipidemic group(the level of HDL-Cholesterol in the rest of the groups also decreased but not significantly as compared to hyperlipidemic control (Table 5).

Table 6. Serum Activity of Cardiac Marker Enzymes (Lactate Dehydrogenase; LDH and Creatine Kinase; CK) of an Induced Hyperlipidemic Rats Treated with Flavonoid-rich Extract of C.micranthum and Atorvastatin for 2 Weeks

\begin{tabular}{lll}
\hline Parameters/Groups & LDH(U/L) & CK (U/L) \\
\hline Group I (NC) & $1383.92 \pm 181.91^{\mathrm{a}}$ & $155.00 \pm 4.990$ \\
Group II (HC) & $3617.44 \pm 686.20^{\mathrm{b}}$ & $214.58 \pm 76.33^{\mathrm{a}}$ \\
Group III $(100 \mathrm{mg} / \mathrm{kg})$ & $1490.79 \pm 243.28^{\mathrm{c}}$ & $44.71 \pm 18.49^{\mathrm{b}}$ \\
Group IV $(200 \mathrm{mg} / \mathrm{kg})$ & $1863.49 \pm 131.92^{\mathrm{d}}$ & $37.14 \pm 12.27^{\mathrm{c}}$ \\
Group V $(400 \mathrm{mg} / \mathrm{kg})$ & $1717.22 \pm 119.53^{\mathrm{e}}$ & $40.24 \pm 4.580^{\mathrm{d}}$ \\
Group VI $(\mathrm{AS})$ & $2265.57 \pm 111.19^{\mathrm{f}}$ & $218 \pm 27.740^{\mathrm{e}}$ \\
\hline
\end{tabular}

Values are expressed as mean \pm SME;Values with different superscript letter $(\mathrm{a}, \mathrm{b}$ and c) differ significantly at $p<0.05$. ( $\mathrm{LDH}=$ lactate dehydrogenase, $\mathrm{CK}=$ creatine kinase, $\mathrm{NC}=$ normal control, $\mathrm{HC}=$ hyperlipidemic control, $\mathrm{AS}=$ atorvastatin)

Table 6 illustrates effect of flavonoid-rich and atorvastatin treatment on cardiac marker enzymes in hyperlipidemic induced rats. The activities of LDH decreased significantly $(p<0.05)$ in the flavonoid-rich and atorvastatin treated groups as compared to hyperlipidemic control group (group II). LDH content in the normal group was significantly lower compared to hyperlipidemic control (Table 6). CKactivity significantly $(p<0.05)$ decreased in the flavonoids-rich treated groups compared to hyperlipidemiccontrol (group II). The activity significantly increased in the atorvastatin treated group (group VI) as compared to medium dose treated group(group IV) and high dose treated (group V).

\section{Discussion}

Oxidative stress-related diseases can be prevented or managed by antioxidants and the therapeutic effects of many medicinal plants have been hypothesized to result from the free radical scavenging and antioxidant activity of the constituent antioxidant phytochemicals notably phenols, flavonoids and tannins [15]. From the result of this study, the percentage flavonoids content in the $C M$ signifies that flavonoid take a significant proportion in the plant's leaf extract, and the percentage yield of flavonoid in the extract shows that, although, there may be other impurities but the flavonoid is the dominant and active constituent of the methanol extract. This is in accordance with the study conducted by D'agostinoet al. [16] using the extract from $C M$ where flavonoid presence was confirmed. The presence of $\mathrm{OH}$ in the structure of compounds characterized by GC-MSfrom fraction of methanol leaf extract of $C M$ is responsible for antioxidant activity and hence radical scavenging activity. The widely acclaimed beneficial effect of flavonoids in human health are mainly due to their radical scavenging and metal chelation properties in which the hydroxyl functional groups are involved [17].

The disorder of lipid metabolism is a key player for the occurrence of cardiovascular diseases and particularly heart disease [18]. From the results of this study, a significant decrease in TC level was observed due to the antioxidant activity of flavonoid which prevents the oxidative modification of LDL-C 
and hence prevents a condition where LDL could release its components. An invitro study conducted by Kerry and Abbey, [19] confirmed that, by scavenging radicals, flavonoids inhibits LDL oxidation. This confirmed the protective effect of flavonoid against CVDs. This is because reduction in plasma TC level will reduce the risk factor for CVDs [20]. Significant decrease in TG is also observed between flavonoid high-dose treated group and hyperlipidemic control group, this implies that, high dose of flavonoid-rich portion of $C M$ is the most effective in the reduction of TG. Decrease in TC and TG levels signifies serious decrease in the risk for CVDs, because, an increased level of TG is both independent and synergistic risk factor for CVD [21]. Significant increase in HDL-C level in flavonoid high and medium dose treated groups could be due to high expression and activity of lecithin cholesterol acyltransferase (LCAT) which lead to the regulation of blood lipid [22] and decrease in the level of LDL-C, which in turn reduces the risk for CVDs [23]. Significant decrease in LDL-C was also observed in all the groups except hyperlipidemicgroup , this may be due to The antioxidant activity of flavonoid which prevent oxidative modification of LDL-C [19] and the decrease in the TC, increased activity of LCAT and hence HDL-C. Significant decrease in AI as observed in all the treated groups was due the decrease in the level of TC and increase in HDL-C level. This signifies a decreased risk for CVDs [24]. Significant decrease in TC, LDL, and AI observed in the atorvastatin treated groups could be attributed to the inhibition effect of atorvastatin on HMG-COA reductase, which reduces denovo synthesis of cholesterol, increasing expression of LDL receptors on hepatocytes, decreasing LDL-C in the blood and results in slight increase in HDL-C. Recent study have shown that in patients suffering from acute coronary syndrome, high dose of artovastatin treatment may play a plaque stabilizing role [25].The significant decrease in weight observed in the treated groups (Group III, IV, V and VI) is related to the significant decrease in the TC, TG, LDL-C and AI, due to the fact that increase in fats is associated with increase in weight. Serum CK activity is a more sensitive indicator of early stage of myocardial ischemia whereas LDH levels give a rough estimate of the extent of injury to myocardial tissues [26]. Since the levels of these cellular enzymes present in blood are directly related to the intactness or integrity of the plasma membrane of the cardiac cells, then, the reduction in serum levels of the marker enzymes(LDH and CK) could be due to the antioxidant action of flavonoid on maintaining cardiac membrane integrity and restricting the leakage of these enzymes into blood stream. This is justified by a study carried out by Aroraet al.[27], which stated that flavonoid have the ability to stabilize membrane by decreasing their fluidity and penetrating into the hydrophobic core of the membrane.

\section{Conclusion}

The result of this work clearly showed a significant lowering potential of flavonoid-rich portion of $C M$ on lipid content and cardiac marker enzymes as observed from decreased level of LDL-C, TG, TC, LDH and CK and increased level of HDL-C. Thus, can be concluded that, the flavonoid extract of $C M$ improves lipid profile and cardiac marker enzymes, hence, decrease significantly the risk for cardiovascular diseases in diet induced hyperlipedemic rats.

\section{Acknowledgements}

The authors wish to sincerely thank the staff and the Department of Biochemistry, Bayero University,Kano-Nigeria for providing us with enabling atmosphere to conduct this study. We are also highly grateful to Tertiary Education Trust Fund (TETFUND) for sponsoring this presentation and the entire conference.

\section{References}

[1] Zhao, W. H., Zhang, J., You, Y., Man, Q. Q., Li, H., Wang, C. K., Zhai, Y., Li, Y., Jin, S. G., \& Yang, X. G. (2005). 
Epidemiologic characteristics of dyslipidemia in people aged 18year and over in china. Chinese Journal of preventive medicine, 39, 306-310.

[2] Saravana, K. A., Avijit M., \& Saravanan, V, S. (2008). Antihyperlipidemic activity of Camelliasinensis leaves in Triton WR-1339 induced albino rats. Pharmacognosy Magazine, 4(13), 60-64.

[3] Bodimon, L., Vilahar, G., \& Padro, T. (2010). Nutraceuticals and atherosclerosis: Human trials. Cardiotherapy, 20(4), 202-21.

[4] Reiner, B. S., \& Tedeschi, R. (2006). Epidemiologic characteristics of dyslipidemia in people aged 18year and over in china. Chinese Journal of preventive medicine, 39, 306-310.

[5] Jadeja, R. N., Thounaojam, M. C., Ansarullah, D. R. V., \& Ramachandran, A. V. (2010). ClerodendronglandulosumColeb., Verbenaceae, ameliorates high fat diet-induced alteration in lipid and cholesterol metabolism in rats. ReviewBrasil De Farmacognosi, 20, 117-123.

[6] Gholam, P. M., Flancbaum, L., Machan, J. T., Charney, D. A., \& Kotler, D. P. (2007). Non-alcoholic fatty liver diseases in severely obese subject. American Journal of Gastroenterology, 102, 399-408.

[7] Abdul'azeez, M. (2011). Effect of Penstrohebicalyculata on Lipid profileof induced hyperlipidemicwistarrats. Journal of Medicinal Plants Research, 5(4), 490-494.

[8] Arai, Y., Watanabe, S., Kimira, M., Shimoi, K., Mochizuki, R., \& Kinae, N. (2000). Dietary intakes of flavonols, flavones and isoflavones by Japanese women and the inverse correlation between quercetin intake and plasma LDL cholesterol concentration. Journal Nutrition, 130, 2243-50.

[9] Wilson, P., D’Agostinho, R. B., \& Levy, D., et al. (1998). Prediction of coronary heart disease using risk factor categories. Circulation, 97, 1837-1847.

[10] Yakubu, M. T., Akanji, M. A., \& Oladiji, A. T. (2007). Male sexual dysfunction and methods used in assessing medicinal plants with aphrodisiac potentials. Pharmacognosy Review, 1(1), 49-56.

[11] OECD. (1993). Join project project on the evaluation of quantitative determination of chemical compounds. OECD Environment Monograph no. 68. OECD/GD(93)126.

[12] National institute of health (NIH). (2006). Medicinal plant analysis on phytochemical. Geneva, 2(7).

[13] Bohm, B. A., \& Kocipai-Abyazan, R. (1994). Flavonoids and condensed tannins from the leaves of Vaccinumreticulation and Vaccinumcalciymium. Pacificscience, 48, 458-463.

[14] Akuntaynak, B. Z., \& Ozbok, E. (2005). Histological assessment of obesity induced NAFLD in female obese rats. Europian Journal of General Medicine, 2(3), 100-109.

[15] Vinson, J. A., Jang, J., Dabbagh, Y. A., Serry, M. M., \& Cai, S. (1995). Plant phenols exhibit lipoprotein-bound antioxidant activity using an in vitro model for heart disease. Journal of Agricultural and Food Chemistry, 43, 2798-2799.

[16] D' Agostino, M., Biagi, C., Feo, V., Zollo, F., \& Pizza, C. (1990). Flavonoids of Combretummicranthum. Fitoterapia, 6(5), 477.

[17] Kessler, M., Ubeaud, G., \& Jung, L. (2003). Anti- and pro-oxidant activity of rutin and quercetin derivatives. Journal Pharmacy and Pharmacology, 55, 131-142.

[18] Carlson, L. A., Bottiger, L. E., \& Ahfeldt, P. E. (1979). Risk factors for myocardial infarction in the Stockholm Prospective Study. A 14-year follow-up focusing on the role of plasma triglycerides and cholesterol. Acta Medica Scandinavia, 206, 351-360.

[19] Kerry, N. L., \& Abbey, M. (1997). Red wine and fractionated phenolic compounds prepared from red wine inhibit low density lipoprotein oxidation in vitro. Atherosclerosis, 135, 93-102.

[20] McBride, P. E. (2007). Triglycerides and risk for coronary heart disease. JAMA, 298, 336-338.

[21] Lichtennstien, A. H., Appel, L. J., Brands, M., Carnethon, M., Daniels, S., Franch, H. A., Franklin, B., Kris-Etherton, P., Harris, W. S., Howard, B., Karanja, N., Lefever, M., Rudel, L., Sacks, F., Horn, L., Winston, M., and Wylie-Rosett, J. (2006). Summary of American Heart Association 2006: Diet and Lifestyle 
Recommendations Revision. Arteriosclerosis, Thrombosis and Vascular Biology, 26, 2186-2191.

[22] Zhang, L., Yang, Y., Yu, L., Wang, Y., Liu, L., \& Fan, X. (2011). Cardioprotective effects of Glycyrrhizauralensisextract against Doxorubicin-induced toxicity. International Journal of Toxicology, 30(2), 181-189.

[23] Shen, G. X. (2007). Lipid disorders in diabetes mellitus and current managements. Current Pharmaceutical Analysis, 3, 17-24.

[24] Meng, H. T., Don, J. N., \& Bradly, G. (2004). Pioglitazone reduces atherogenic index of plasma in patient's type 2 diabetes. Clinical Chemistry, 50(7), 1184-1188.

[25] Rosa, G. M., Carbone, F., Parodi, A., Massimelli, E. A., Brunelli, C., Mach, F., Vuilleumier, N., \& Montecucco, F. (2014). "=Update on the efficacy of statin treatment in acute coronary syndromes. Europian Journal of Clinical Investigation, 44(5), 501-15.

[26] Chen, Y. F., Kobayashi, S., \& Chen, J. (2008). Short term triiodo-l-thyronine treatment inhibits cardiac myocyte apoptosis in border area after myocardial infarction in rats. Journal of Molecular and Cellular Cardiology, 44(1), 180-187.

[27] Arora A., Byrem, T. M., Nair, M. G., \& Strasburg, G. M. (2000). Modulation of liposomal membrane fluidity by flavonoids and isoflavonoids. Archive of Biochemistry and Biophysics, 373, 102-109.

A. Babandi was born, brought up, and educated in Nigeria. A. Babandi had a B.Sc., M.Sc., and Ph.D. (in view) in biochemistry from Bayero University, Kano and University of Nigeria respectively. Currently A. Babandi is working in the area of drug discovery from natural sources and "green insecticides" Also, A. Babandi has specific interest in antioxidants, oxidative stress in degenerative diseases, bioinformatics and biotechnology. 